\title{
The Complexities of Resistance to Bevacizumab
}

\author{
Han Shen, Kerrie L. McDonald* \\ Cure for Life Neuro-Oncology Group, Lowy Cancer Research Centre, Prince of Wales Clinical School, University of New South, \\ Wales, Sydney, Australia. \\ Email: han.shen@student.unsw.edu.au, *k.mcdonald@unsw.edu.au
}

Received July 2 $2^{\text {nd }}, 2012$; revised August $5^{\text {th }}, 2012$; accepted August $16^{\text {th }}, 2012$

\begin{abstract}
Glioblastoma is a highly malignant primary tumor of the central nervous system tumor with a poor survival rate. The treatment of glioblastoma is shifting from a purely cytotoxic approach to one that incorporates anti-angiogenic agents. Bevacizumab (Avastin ${ }^{\circledR}$; Roche) was approved in the United States for the treatment of recurrent glioblastoma in May 2009 and showed encouraging results. However, "rebound" tumor progression with accelerated clinical decline has been observed after cessation of bevacizumab therapy in patients with high-grade gliomas and there is no effective treatment for the recurrent glioblastoma after bevacizumab failure. This review summarizes the characteristics of glioblastoma as well as the possible mechanisms of recurrence after anti-angiogenic therapy. Furthermore, alterations of the key molecular pathways and glycometabolic remodeling in glioblastoma are also discussed within. A better understanding of the complexities underpinning the resistance to bevacizumab and the combination of targeting cancer metabolism and anti-VEGF therapy may ultimately result in new modes of treatment, which hopefully improve the overall survival for patients diagnosed with glioblastoma.
\end{abstract}

Keywords: Glioblastoma; Bevacizumab; Relapse; Glycolysis

\section{Introduction}

Glioblastoma (GBM) is the most common and aggressive primary malignant brain tumor in adults. More than 50,000 primary brain tumors are diagnosed in the United States each year, 31\% of which are gliomas. Of these, more than half are GBM [1]. Based on histological characteristics, World Health Organization (WHO) classifies GBM as a grade IV astrocytoma, which is the most malignant grade [2].

Surgical intervention aims to maximally resect tumor thus reducing the mass effect and tumor burden. However, it is not curative due to infiltrative nature of the disease. Postoperative radiotherapy (RT) was considered as the mainstay of treatment for GBM patients in early 1980s, as it extended median survival from 3 - 4 months to a range of 7 - 12 months [3-6]. The efficacy of chemotherapy for GBM had historically been frustrating until 2002, a meta-analysis of 12 trials of either adjuvant or concomitant chemotherapy plus RT showed a modest but significant survival increase when chemotherapy was administered in combination with RT [7]. Chemotherapy as the standard of care for GBM was established in 2005, when Stupp et al. demonstrated that the addition of concomitant and adjuvant temozolomide (TMZ) improved

"Corresponding author. median survival [6]. At the present time, the recommendations for GBM therapy are that all newly diagnosed GBM patients should be initially considered for maximum tumor resection (>98\%) when feasible, concomitant TMZ/RT 2 - 6 weeks after surgery, and then adjuvant TMZ for 6 months.

In spite of these significant improvements in the multimodality treatment of GBM and the establishment of standard therapy, most patients experience a recurrence inevitably and the prognosis remains poor. The median survival is only 12 - 15 months for patients with GBM after initial diagnosis followed by standard treatment [6]. Once the disease progression occurs, available salvage chemotherapies are administered but are typically unsuccessful, which leads to disease-related death.

\section{Rationale of Anti-Angiogenic Therapy for Glioblastoma}

Because of its dismal prognosis with the current comprehensive treatment, intense efforts are underway to develop new treatment approaches to improve the prognosis and the quality of life of patients with GBM. At present, the etiology of GBM is still unknown. However, the dependency of tumor growth on angiogenesis has identified this trait as a promising therapeutic target. Angiogenesis is the process of new blood vessel formation, 
which is prevalent during embryonic development but is highly restricted in healthy adults. In a normal adult vessel only $0.01 \%$ of the endothelial cells are dividing at any given time and as such the quiescent adult vasculature has a very low rate of turnover $[8,9]$. However, endothelial cells retain the ability to divide promptly and angiogenesis can occur in some exceptional physiological situations such as wound healing, placental growth and embryo implantation. Angiogenesis also occurs in pathologic processes such as rheumatoid arthritis, scleroderma, and diabetic retinopathy [10]. Angiogenesis has also been implicated in the growth and metastasis of tumors. It is required for tumor growth when the diameter of a solid tumor is beyond $2-3 \mathrm{~mm}$ owning to the limited oxygen and nutrient diffusion [11]. GBM has been considered as one of the most vascularized human tumors, making them especially attractive targets for angiogenesis inhibitors [12]. Therefore, many preclinical studies have used GBM as a tumor model of angiogenesis.

Vascular endothelial growth factor (VEGF) has been implicated as a central mediator of angiogenesis in GBM, with the highest levels of VEGF expression centralized in relative hypoxic regions, such as areas of necrosis and endothelial cell proliferation [13]. A correlation between tumor grade and VEGF expression in gliomas has been confirmed by various in vitro and in vivo studies [14-16]. Additionally, studies in animal models have shown that inhibiting VEGF function inhibits the growth of glioma cells in vivo and results in regression of blood vessels [17].

The adult nervous system harbors neural stem cells which are capable of self-renewal, proliferation, and differentiation into distinctive mature cell types [18]. There is growing evidence that neural stem cells or related progenitor cells can be transformed into cancer stem cells which give rise to malignant gliomas [19-21] and contribute to the resistance of malignant gliomas to standard treatments [22-25]. Furthermore, recent studies suggest that glioma stem cells secrete VEGF, thereby promoting angiogenesis in the tumor micro-environment [26,27], whereas VEGF has been implicated in promoting tumorigenesis and angiogenesis of human glioma stem cells [28]. These findings indicate that anti-angiogenic agents may not only reduce blood supply to tumors but also target glioma stem cells to inhibit their functioning. Given these findings, blocking angiogenesis has been suggested as a potential therapy for patients with GBM to inhibit tumor growth.

\section{Bevacizumab, a Promising, yet Controversial Anti-Angiogenic Agent for Glioblastoma}

Bevacizumab (Avastin ${ }^{\circledR}$, Roche) was developed as a humanized monoclonal antibody to bind VEGF-A, pre- venting the interaction and activation of VEGF receptors $[29,30]$. This drug has been approved by the United States Food and Drug Administration (FDA) for its use in clinical treatment of metastatic colorectal cancer, advanced non-squamous non-small cell lung cancer and metastatic renal cell carcinoma.

On May 5th, 2009, the United States FDA granted an accelerated approval to bevacizumab for its use as a single injection agent for patients with recurrent GBM following prior therapy. This approval was based on the positive results in two prospective phase II studies which showed improvements in patient outcomes alone or in combination with chemotherapy [31]. The primary endpoints were radiographic response and progression free survival (PFS) at 6 months. Specifically, the assessment of radiographic response to therapy in high-grade gliomas (HGG) was based on magnetic resonance imaging (MRI) and the definition of PFS was the time elapsed between treatment initiation and tumor progression or death from any cause, with censoring of patients who are lost to follow-up. The first phase II trial was performed to test the efficacy of intravenous administration of bevacizumab and irinotecan, a topoisomerase I inhibitor, for 35 recurrent GBM patients [32]. The 6-month PFS (PFS6) was 46\%, and the median overall survival was 10.5 months. The other larger, randomized, non-comparative phase II study, coined the BRAIN study (AVF3708 g), was performed to investigate the efficacies using bevacizumab alone or in combination with irinotecan for 167 patients with recurrent GBM [33]. In Australia, based on the review of quality, safety and efficacy data, the Therapeutic Goods Administration (TGA) also approved the registration of Avastin containing bevacizumab for the new indication as a single agent for the treatment of patients with recurrent GBM after standard therapies. Following the approval for bevacizumab for recurrent GBM, many phase II studies have been performed to explore the efficacies of bevacizumab combined with different targeting therapies or radiotherapy to malignant gliomas. The results of these studies indicate that additional therapy to bevacizumab can be a promising strategy for GBM treatment (Table 1). Although bevacizumab was widely used in this indication in the United States and in some European countries even before the approval of the U.S. FDA, the marketing application to European Medicines Agency was rejected due to existing issues with regard to dosing, timing and efficacy [34].

\section{Mechanisms of Resistance to Anti-Angiogenic Therapy}

The molecular and cellular basis of the rebound effect after bevacizumab failure is still vague. There are multiple putative mechanisms of resistance to anti-angiogenic 
Table 1. Outcomes with phase II trials of bevacizumab-containing therapy in recurrent high grade gliomas. (HGG, high grade glioma; BV, bevacizumab; CA, carboplatin; I, irinotecan; ET, etoposide; ER, erlotinib; CE, cetuximab; TMZ, temozolomide; HFSRT, hypofractionated stereotactic radiotherapy; IMRT, intensity modulated radiation therapy; CT, chemotherapy; RT, radiotherapy; CR, complete response; PR, partial response; SD, stable disease; PD, progressive disease; NE, not evaluable; NA, not available; m, months; w, weeks).

\begin{tabular}{|c|c|c|c|c|c|c|c|c|c|c|c|}
\hline \multirow{2}{*}{$\begin{array}{l}\text { Study (author) } \\
\text { BV + CT }\end{array}$} & \multicolumn{2}{|c|}{ Tumor type } & \multirow[t]{2}{*}{ Regimen } & \multicolumn{5}{|c|}{ Radiographic response rate (RRR) } & \multicolumn{2}{|c|}{$\begin{array}{l}\text { Progression free } \\
\text { survival (PFS) }\end{array}$} & \multirow[t]{2}{*}{$\begin{array}{r}\text { Overall } \\
\text { survival }\end{array}$} \\
\hline & GBM & $\begin{array}{l}\text { Other } \\
\text { HGG }\end{array}$ & & CR & PR & SD & PD & $\mathrm{NE}$ & Median PFS & PFS-6 & \\
\hline Reardon et al. [35] & 40 & & $\mathrm{BV}+\mathrm{CA}+\mathrm{I}$ & NA & $33 \%$ & $53 \%$ & $13 \%$ & NA & $5.9 \mathrm{~m}$ & $46.5 \%$ & $8.3 \mathrm{~m}$ \\
\hline Reardon et al. [36] & 25 & & $\mathrm{BV}+\mathrm{CA}+\mathrm{I}$ & NA & NA & $80 \%$ & $16 \%$ & $4 \%$ & $2.3 \mathrm{~m}$ & $16 \%$ & $5.8 \mathrm{~m}$ \\
\hline Reardon et al. [37] & 23 & & $\mathrm{BV}+\mathrm{ET} / \mathrm{TMZ}$ & NA & NA & $52 \%$ & $43 \%$ & $4 \%$ & $7.3 \mathrm{w}$ & $4.4 \%$ & NA \\
\hline Desjardins et al. [38] & 32 & & $\mathrm{BV}+\mathrm{TMZ}$ & NA & $28 \%$ & $50 \%$ & $22 \%$ & NA & $15.8 \mathrm{w}$ & $18.8 \%$ & $37.1 \mathrm{w}$ \\
\hline \multirow[t]{2}{*}{ Reardon et al. [39] } & & 32 & $\mathrm{BV}+\mathrm{ET}$ & $7 \%$ & $17 \%$ & $72 \%$ & $13 \%$ & NA & $24 \mathrm{w}$ & $40.6 \%$ & $63.1 \mathrm{w}$ \\
\hline & 27 & & $\mathrm{BV}+\mathrm{ET}$ & $4 \%$ & $19 \%$ & $73 \%$ & $7 \%$ & NA & $18 \mathrm{w}$ & $44.4 \%$ & $46.4 \mathrm{w}$ \\
\hline \multirow[t]{2}{*}{ Sathornsumetee et al. [40] } & 25 & & $\mathrm{BV}+\mathrm{ER}$ & $4 \%$ & $46 \%$ & $42 \%$ & $8 \%$ & NA & NA & $28 \%$ & $42 \mathrm{w}$ \\
\hline & & 32 & $\mathrm{BV}+\mathrm{ER}$ & $3 \%$ & $28 \%$ & $44 \%$ & $22 \%$ & NA & NA & $71 \%$ & $44 \mathrm{w}$ \\
\hline Hasselbalch et al. [41] & 43 & & $\mathrm{BV}+\mathrm{CE}$ & \multicolumn{5}{|c|}{ 34\% (RRR) } & $29 \mathrm{w}$ & $30 \%$ & NA \\
\hline Stark-Vance et al. [42] & 11 & 10 & $\mathrm{BV}+\mathrm{I}$ & $5 \%$ & $38 \%$ & $52 \%$ & NA & NA & NA & NA & NA \\
\hline Pope et al. [43] & 10 & 4 & $\mathrm{BV}+\mathrm{I}$ or $\mathrm{ET}$ & NA & $50 \%$ & $21 \%$ & NA & NA & NA & NA & NA \\
\hline Vredenburgh et al. [44] & 23 & & $\mathrm{BV}+\mathrm{I}$ & $3 \%$ & $59 \%$ & $34 \%$ & NA & NA & NA & $30 \%$ & $9.23 \mathrm{~m}$ \\
\hline \multirow[t]{2}{*}{ Vredenburgh et al. [44] } & 23 & & $\mathrm{BV}+\mathrm{I}$ & $4 \%$ & $56 \%$ & $35 \%$ & $4 \%$ & NA & $20 \mathrm{w}$ & $30 \%$ & $40 \mathrm{w}$ \\
\hline & & 9 & $\mathrm{BV}+\mathrm{I}$ & NA & $67 \%$ & $33 \%$ & NA & NA & $30 \mathrm{w}$ & $56 \%$ & NA \\
\hline Vredenburgh et al. [32] & 35 & & $\mathrm{BV}+\mathrm{I}$ & $57 \%$ & NA & $24 \%$ & NA & NA & $5.5 \mathrm{~m}$ & $46 \%$ & $9.7 \mathrm{~m}$ \\
\hline Norden et al. [45] & 33 & & $\mathrm{BV}+\mathrm{CT}$ & NA & NA & NA & NA & NA & $5.5 \mathrm{~m}$ & $42 \%$ & $8.2 \mathrm{~m}$ \\
\hline Narayana et al. [46] & 37 & 24 & $\mathrm{BV}+\mathrm{I} / \mathrm{CT}$ & NA & NA & NA & NA & NA & $5 \mathrm{~m}$ & NA & $9 \mathrm{~m}$ \\
\hline \multirow[t]{2}{*}{ Nghiemphu et al. [47] } & 123 & & $\mathrm{BV}+\mathrm{CT}(\mathrm{n}=44)$ & NA & NA & NA & NA & NA & $4.25 \mathrm{~m}$ & $41 \%$ & $9 \mathrm{~m}$ \\
\hline & & & $\mathrm{CT}(\mathrm{n}=79)$ & NA & NA & NA & NA & NA & $1.82 \mathrm{~m}$ & $18 \%$ & $6.1 \mathrm{~m}$ \\
\hline \multirow[t]{2}{*}{ Poulsen et al. [48] } & 27 & & $\mathrm{BV}+\mathrm{I}$ & \multicolumn{5}{|c|}{$30 \%$ (RRR) } & $22 \mathrm{w}$ & $40 \%$ & $28 \mathrm{w}$ \\
\hline & & 22 & $\mathrm{BV}+\mathrm{I}$ & \multicolumn{5}{|c|}{$15 \%(\mathrm{RRR})$} & NA & $33 \%$ & $32 \mathrm{w}$ \\
\hline \multirow[t]{2}{*}{ Zuniga et al. [49] } & 37 & & $\mathrm{BV}+\mathrm{I}$ & \multicolumn{5}{|c|}{ 68\% (RRR) } & $7.6 \mathrm{~m}$ & $63.7 \%$ & $11.5 \mathrm{~m}$ \\
\hline & & 14 & $\mathrm{BV}+\mathrm{I}$ & \multicolumn{5}{|c|}{ 79\% (RRR) } & $13.4 \mathrm{~m}$ & $78.6 \%$ & NA \\
\hline Gilbert et al. [50] & 57 & & $\mathrm{BV}+\mathrm{I}$ & NA & NA & NA & NA & NA & NA & $37 \%$ & NA \\
\hline \multicolumn{12}{|l|}{$\mathrm{BV}+\mathrm{RT}$} \\
\hline Gutin et al. [51] & 20 & & $\mathrm{BV}+\mathrm{HFSRT}$ & $50 \%$ & NA & NA & NA & NA & NA & $65 \%$ & $12.5 \mathrm{~m}$ \\
\hline Mohile et al. [51] & 10 & 2 & $\mathrm{BV}+\mathrm{IMRT}$ & $7 \%$ & NA & NA & NA & NA & NA & $76 \%$ & NA \\
\hline \multicolumn{12}{|l|}{ Single-agent BV } \\
\hline Friedman et al. [33] & 167 & & $\mathrm{BV}(\mathrm{n}=85)$ & $28 \%$ & NA & NA & NA & NA & NA & $42.6 \%$ & $9.2 \mathrm{~m}$ \\
\hline Kreisl et al. [52] & 48 & & $\mathrm{BV}, \mathrm{BV}+\mathrm{I}$ & $35 \%$ & NA & NA & NA & NA & $16 \mathrm{w}$ & $29 \%$ & $31 \mathrm{w}$ \\
\hline Chamberlain et al. [53] & 50 & & $\mathrm{BV}$ & $42 \%$ & NA & $42 \%$ & NA & NA & NA & $42 \%$ & $8.5 \mathrm{~m}$ \\
\hline Raizer et al. [54] & 50 & 11 & $\mathrm{BV}$ & NA & $25 \%$ & $50 \%$ & NA & NA & $3.9 \mathrm{~m}$ & $32 \%$ & $6.6 \mathrm{~m}$ \\
\hline
\end{tabular}


therapy involved. Generally, two principal modes of resistance to anti-VEGF agents are proposed: adaptive resistance and intrinsic resistance.

\subsection{Adaptive Resistance to Anti-Angiogenic Therapy}

The early "starvation hypothesis" of anti-angiogenic therapy is considered to destroy the tumor vasculature, by means of depriving the oxygen and nutrients supply for the tumor. However, increasing evidence shows that mechanisms of anti-angiogenic therapy are more intricate and may also rely on tumor types [55]. For GBM, a highly vascularized primary brain tumor, it has been demonstrated that anti-angiogenic therapy not only inhibits its vascularization but also has anti-tumor effects [56]. More recently, a hypothesis raised by Jain et al. postulated that certain anti-angiogenic agents were able to transiently "normalize" aberrant tumor vasculature of solid tumors accompanied by increased blood flow, such that the normalized vasculature facilitated efficient delivery of oxygen and chemotherapeutic agents [57]. Nevertheless, queries have been raised by some other pre-clinical studies whose data show a reduction in tumor perfusion and oxygenation in xenograft models with patient-derived tumor [58]. In addition, some studies considered that anti-angiogenic therapy would compromise the delivery of chemotherapeutic agents and oxygen by destroying vasculature, which gave rise to a hypoxic micro-environment thereby rendering chemotherapy as well as radiotherapy less effective. A reduced TMZ concentration within xenograft intracranial gliomas has been detected after anti-VEGF treatment with TNP-470, indicating that the actions of angiogenesis inhibitor on tumor angiogenesis can produce a reduction in the tumor concentration of co-administered anti-cancer agents [59]. For the radiotherapy, the same anti-angiogenic agent was tested in combination with fractionated radiotherapy indicative of less efficacy due to inhibited re-oxygenation by anti-angiogenic therapy [60]. Nevertheless, by investigating whether anti-VEGF treatment produces detrimental effects on tumor vascular function and oxygenation that could compromise adjuvant therapies, researchers concluded that the reductions in tumor oxygenation due to anti-angiogenic treatment were transient, and initial pathophysiological deficiencies that could compromise conventional therapies over the short-term may be of less relevance when administered over more extended treatment schedules [61]. As Jain et al. mentioned, improved efficacy of anti-angiogenic therapy is dependent on both optimized therapeutic dose/combination and the treatment schedule with proper time window [57], and this hypothesis was further verified by a recent study which was performed in non-small cell lung cancer (NSCLC) patients using positron emission tomography
(PET) and radio-labeled docetaxel ([11C] docetaxel) [62]. Even so, both the optimized therapeutic dose/combinationn and proper time window for treatment still remain to be investigated.

In normal tissues, a balance between pro- and anti-angiogenic factors exists and it tips in favor of the stimulators in both physiological and pathological angiogenesis. In pathological angiogenesis, the imbalance persists and inclines to pro-angiogenesis, leading to tumor abnormal vascularization. It is proposed that anti-angiogenic therapies initially improved both the structure and the function of tumor vessels. However, sustained or aggressive antiangiogenic regimens may eventually prune these vessels, resulting in the remaining vasculature being both resistant to further treatment and inadequate for delivery of drugs or oxygen, then tumors eventually be- come resistant to the therapy and adopt a highly infiltrative and invasive phenotype [57].

Prominent vessel pruning and excessive inhibition of new vessel growth by anti-angiogenic agents are able to induce or aggravate hypoxia, which not only up-regulates the production of other pro-angiogenic factors, leading to VEGF-independent revascularization (evasive resistance), but also activates transcription of some proto-oncogenes resulting in tumor regrowth, invasion and metastasis.

1) Up-regulation of pro-angiogenic factors/signaling pathways

Evidence for resistance to anti-angiogenic agents as a result of the up-regulation of pro-angiogenic factors stemmed from pre-clinical experimentation in a genetically modified murine model. In this model, mice were treated with monoclonal antibodies against VEGFR. A transient response was evidenced by tumor stasis and tumor vascular reduction to the anti-VEGFR agent, however extensive tumor regrowth was observed with typically dense tumor vasculature [63]. Compared to untreated tumors, the recurrent tumors were accompanied by heightened mRNA expression levels of the pro-angiogenic factors including fibroblast growth factor 1 (FGF1), FGF2, ephrin A1 (EFNA1), EFNA2, and angiopoietin1 (ANGPT1). Remarkably, regions of acute hypoxia were found at the peak of response phase suggesting that the up-regulation of most of these genes could be as a result of the hypoxic conditions. An increased number of pro-angiogenic factors were also implicated in the late phase of resistance and included angiogenin (Ang), interleukin-1 $\beta$ (IL-1b), basic fibroblast growth factor (bFGF), tumor necrosis factor- $\alpha$ (TNF- $\alpha$ ), transforming growth factor- $\alpha$ (TGF- $\alpha$ ), tissue inhibitor of matrix metalloproteinase-1,2 (TIMP-1,2). Additionally, pre-clinical studies have suggested that evasions of anti-angiogenic therapy are adaptive non-genetic mechanisms such as transcriptional up-regulation which allow tumor cells to find alternative ways for sustaining tumor 
regrowth while the anti-angiogenic agent remains ineffective [64].

Hypoxia-induced recruitment of various bone marrow-derived cells (BMDCs) has been considered to play an important role in resistance to anti-angiogenic therapy. Anti-VEGF therapy is typically combined with chemotherapy to increase its anti-tumor effectiveness, by sensitizing endothelial cells to cytotoxic damage, and to impair the survival and regrowth of endothelial cells. However, recruitment of BMDCs after chemotherapy and anti-angiogenic therapy can revascularize the tumor [65,66], which is referred as "vasculogenic rebound" [67]. Under hypoxic conditions, a heterogeneous population of BMDCs is recruited to promote angiogenesis. The cell population consists of endothelial and pericyte progenitors which differentiate into endothelial cells forming the inner lining of blood vessels and pericytes to support blood vessels, respectively. Apart from supporting the normal function of blood flow, pericytes also protect endothelial cells from anti-angiogenic therapies by inducting autocrine VEGF-A signaling, and have thus been implicated in the resistance to vasculature-targeting drugs [68]. Besides the aforementioned two progenitors, there are other angiocompetent BMDCs involved, including Tie2-expressing monocytes (TEMs), tumor-associated macrophages (TAMs), neutrophils, mast cells and integrin alpha M (ITGAM) + lymphocyte antigen 6G (Ly6G) + myeloid-derived suppressor cells, which release angiogenic signals such as VEGF, prokineticin 2 (PROK2) and matrix metalloproteinases (MMPs) [69].

Although VEGF blockade results in the majority of vessels regressing, a few thin vessels remain, densely and tightly covered with pericytes. Protective pericytes presumably assist endothelial cell survival during anti-angiogenic therapy [70]. However, this hypothetical resistance mechanism still remains to be confirmed.

2) Activation of pro-tumor pathways

Blocking angiogenesis shrinks tumors by starving them of oxygen and nutrients. On the other hand, it selects for cell populations which survive longer in oxygen-deprived tumor environments. For these cells, hypoxia induced by vessel regression after anti-VEGF treatment is able to switch on a more invasive and metastatic program as well as up-regulate pro-angiogenic factors. Pre-clinical studies have indicated that hypoxia activated this more aggressive mode predominantly by stimulating the expression of two proteins: scatter factor/hepatocyte growth factor (SF/HGF) and its receptor c-mesenchymal-epithelial transition factor (c-Met) [71]. Normally, SF/HGF and c-Met play essential roles in embryogenesis and organogenesis [72], while this ligandreceptor pair has been implicated in tissue regeneration and wound healing process in adult tissues [73,74]. Upon HGF stimulation, c-Met induces several biological re- sponses that collectively give rise to a complex genetic program referred to as "invasive growth". For brain tumors, overexpression of SF/HGF and c-Met have been found to enhance their tumorigenicity, tumor growth, and tumor-associated angiogenesis [75]. Moreover, the expression levels have been identified to correlate with tumor grade and patient's prognosis [76].

An ideal combined therapeutic mode suggested by related scientists is that instead of just targeting VEGF, a drug which blocks c-Met and avoids the consequence of increasing hypoxia could also be administered. To date, pre-clinical studies have shown that using an orthotopic mouse model of GBM containing a c-Met-activating mutation, local treatment of the one-armed 5D5 (OA5D5) anti-c-Met antibody (MetMAb; Roche) completely inhibited intracranial GBM growth in SF/HGF dependent tumors [77]. In addition, a number of c-Met pathway inhibitors have been or are currently being studied in clinical trials with cancer patients, including therapeutic antibodies binding to SF/HGF and c-Met and small molecule tyrosine kinase inhibitors (TKIs) blocking c-Met kinase specifically $[78,79]$. Of note, a recent phase II study has shown that AMG-102 (rilotumumab) monotherapy was not associated with significant anti-tumor activity in heavily pre-treated patients with recurrent GBM [80]. Another phase II study to evaluate the efficacy and safety of AMG-102 in combination with bevacizumab in patients with recurrent malignant glioma is underway as well [81]. We hope that there will be encouraging outcomes from these phase II studies.

\subsection{Intrinsic Resistance to Anti-Angiogenic Therapy}

1) Redundancy of pro-angiogenic factors

A substantial minority of patients receiving anti-angiogenic therapy fail to show even transitory clinical benefit [82]. Although it is possible that this group of patients reflect rapid adaptive resistance to anti-angiogenic therapy, another pre-existing or intrinsic resistance mechanism might exist. Due to recruitment of FGF2 and other pro-angiogenic factors at a very late stage of disease, tumor angiogenesis could become VEGF-independent leading to a compromised response to anti-VEGF therapy [67]. An analysis of human breast cancer biopsies covering a range from low to high grade malignant tumors revealed that advanced stage breast cancers expressed significantly higher expression of pro-angiogenic factors including FGF2 compared to earlier stage tumors which preferentially expressed VEGF [83]. Therefore, intrinsic levels of pro-angiogenic factors in the advanced stage tumors could sustain angiogenesis, even when treated with anti-VEGF therapy.

2) Role of stem-like cells in resistance to anti-angiogenic therapy 
Several years ago, a population of stem-like cells isolated from malignant gliomas provided a new perspective in cancer biology: the cancer stem cell hypothesis. This stem-like cell population has been proposed to be the cell population of the tumor which is most refractory to treatment [20]. Glioma stem-like cells have been reported to promote angiogenesis via enhanced expression of VEGF and other angiogenic growth factors [26,27]. Especially during the early stage of tumor initiation, the glioma stem-like cell population can constitute a relatively large proportion of the tumor mass and contribute to tumor formation. Thus, it is plausible that the glioma stem-like cells trigger an angiogenic switch by sending the necessary signals during the early stage of tumor growth of primary and metastatic tumors [84]. In addition, an increasing amount of evidence has shown that the hypoxic environment is also able to facilitate the expansion of glioma stem-like cell populations as well as promote a more stem-like phenotype in the non-stem cell glioma cell populations $[85,86]$.

\section{Alterations of the Molecular Pathways: PI3K/AKT and Wnt/ $\beta$-Catenin Signaling Pathways}

The phosphatidylinositol-3-kinase (PI3K)/AKT oncogenic pathway plays a critical role in GBM. Loss of PTEN, a negative regulator of the PI3K pathway, or activated PI3K/AKT pathway that drives increased proliferation, survival, neovascularization, glycolysis, and invasion, is found in $70 \%-80 \%$ of malignant gliomas. Members of the PI3K/AKT signaling pathway can mediate invasion, angiogenesis, and the expression of VEGF in cells [87-89]. This stimulation of VEGF in cancer cells can be regulated by autocrine or by the chronic stimulation by growth factors such as the insulin-like growth factor- 1 and constitutive activation of PI3K/AKT due to loss of the tumor suppressor PTEN [88,89]. From a therapeutic viewpoint, it has been suggested that PI3K inhibitors could be capable of inducing effective killing of cancer cells. Furthermore, many pre-clinical studies have shown potent inhibitory effects of different PI3K/AKT pathway inhibitors alone or in combination with other therapeutic agents to GBM [90,91].

The $\mathrm{Wnt} / \beta$-catenin signaling cascade is another important signal transduction pathway which is overactivated in many human cancers. Extensive data have shown that aberrant $\mathrm{Wnt} / \beta$-catenin signaling plays a crucial role in GBM, including tumorigenesis, cell proliferation, invasion and apoptosis [92-95]. However, the mechanisms involved in the $\mathrm{Wnt} / \beta$-catenin signaling pathway are still elusive and need to be investigated. Previous research has shown that the $\mathrm{Wnt} / \beta$-catenin pathway correlated closely with the progression of gliomas and they suggested it might be a novel prognostic marker for gliomas [96]. In addition, a number of components within this pathway have been confirmed to be implicated in the interaction controlling Wnt-targeted gene expression, which is required for glioma formation [97,98]. As for epigenetic findings, suppression of the Wnt signaling pathway also has been suggested as an effective way for suppressing tumor growth [92,99].

\section{Rechallenge after Bevacizumab Failure}

Bevacizumab has shown encouraging effect as both a single anti-angiogenic agent and in combination with chemotherapy in recurrent GBM. However, after the cessation of bevacizumab therapy or even during the therapy course, patients with GBM inevitably experience tumor recurrence [100]. Recurrent tumors after bevacizumab failure have been reported to be more aggressive with rebound radiographic phenomenon, combined with accelerated clinical decline [100]. This highly aggressive phenotype after anti-VEGF treatment has been found not only from clinical settings but also from pre-clinical studies, which demonstrated that anti-VEGF therapy increased tumor invasion by using in vitro and in vivo models [64,101]. However, there are different opinions in regards to this perspective. Some concluded that increased local invasion and distant metastasis would be induced by anti-angiogenic therapy [102] whereas others considered that the risk of distant or diffuse tumor spread at the time of failure of bevacizumab-containing treatments was not higher than with anti-VEGF-free regimens [103].

No matter what the recurrent pattern is, there is a growing consensus that the recurrent tumor after bevacizumab failure will become more refractory to additional treatment intervention with or without bevacizumab. The introduction of additional agents to bevacizumab has been attempted for patients after bevacizumab failure. However, disease prognosis was extremely poor with median PFS of 37.5 days and 6-month PFS of 2\% [104]. At present, there is no optimal treatment for patients with GBM who progress following bevacizumab failure. It is thus urgent for us to find an effective therapeutic for the recurrent GBM patients who have undergone salvage therapy containing bevacizumab.

A recent pre-clinical study working with a GBM xenograft model derived from patient tumor spheroids discovered that anti-VEGF treatment not only reduced vascular supply but also increased tumor cell invasion [58]. An increase in lactate and alanine metabolites together with an induction of HIF-1 $\alpha$ as well as an up-regulation of the PI3K and the Wnt signaling pathways was observed as a result of bevacizumab treatment. These results indicate that anti-angiogenic therapy could benefit from the adjuvant delivery of drugs targeting specific signaling or metabolic pathways linked to the glycolytic 
metabolism of tumor cells.

\section{Remodeling of Glycolytic Metabolism in Glioblastoma}

A striking difference between normal differentiated cells and tumor cells is different modes of metabolism. Tumor cells produce energy by a high rate of glycolysis rather than by pyruvate oxidation in the mitochondria as most normal cells do. This phenomenon is termed the "Warburg effect" [105]. With this "metabolic transformation", cancer cells swiftly adapt their energy metabolism to the needs of a high proliferation rate and an unfavorable hypoxic/acid microenvironment, which has recently been recognized as an emerging distinguishing feature of cancer cells from normal differentiated cells [106]. A relevant study indicated that such remodeling of the metabolism rendered tumor cell resistant to cell death signals mediated by oxidative damage [107].

Glycolysis is defined as the metabolic process converting glucose to pyruvate which is subsequently incurporated into different metabolic pathways. In aerobic conditions, pyruvate normally enters in the tricarboxylic acid (TCA) cycle where it generates 36/38 moles of ATP after complete oxidative phosphorylation. Under anaerobic condition, pyruvate generates 2 ATP by converting to lactate, which is excreted from the cell together with protons, resulting in an extracellular acidifycation. Although the overall production of ATP during anaerobic glycolysis is much less than it is in aerobic respiration (2ATP versus to 36/38 ATP), tumor cells heavily rely on anaerobic glycolysis even in the presence of adequate oxygen supply, which implies that tumor cells need much more glucose to meet their increased requirements for energy and biosynthetic intermediates [108]. Indeed, most tumor cells show a significant increase in glucose uptake compared to normal tissue cells. Based on this phenomenon, an advanced imaging tool, Positron Emission Tomography (PET) with (18F) deoxyglucose was designed for cancer diagnosis.

There have been many attempts to block the glycolysis in tumor cells using different inhibitors targeting the glycolytic pathway. 2-deoxy-D-glucose (2-DG), an agent which blocks the cellular metabolism of glucose via mimicking glucose, has shown promising results in a number of model systems of cancer. Encouraging results in regard to toxicity of the combining 2-DG with hypofractionated radiotherapy have stemmed from phase I and II clinical trials and its efficacy is currently being evaluated in phase III clinical trials for glioma patients [109]. 3-Bromopyruvate (3-BrPA), a pyruvate analogue, is both an alkylating agent and an inhibitor of glycolysis. 3-BrPA was shown to inhibit tumor growth in a dosedependent fashion in animal models, but the mechanism of action and the toxicity caused by high effective dose are not known for this compound [110]. Apart from these, there have been many compounds developed for targeting the glycolytic pathway, such as Lonidamine (an inhibitor of mitochondrial-bound hexokinase II), Clotrimazole (induces detachment of hexokinase II from mitochondrial membrane) and Dichloracetate (an inhibitor of pyruvate dehydrogenase kinase 2) [111]. Although glycolysis is reduced by these compounds, none of these compounds demonstrate potent tumor growth inhibition. Hence, effective therapy targeting the glycolysis of tumor cells still remains to be explored.

\section{Conclusion}

The results of the phase III trial, AVAglio, which is investigating the efficacy of adding bevacizumab up front to the standard "Stupp" protocol of RT and TMZ will provide critical evidence for its continued use in GBM [112]. There is little doubt that bevacizumab is a very effective steroid "sparing" agent, however its efficacy in reducing tumor growth and improved survival benefits continue to be the topic of heated debate. It is clear that the mechanisms of tumor resistance, either intrinsic to the patients or acquired as a result of anti-VEGF treatment are not completely understood. Overall survival will improve for patients diagnosed with GBM as we gain a better understanding of the complexities that underpin this treatment resistance to anti-VEGF therapies.

\section{REFERENCES}

[1] CBTRUS, “2011 CBTRUS Statistical Report: Primary Brain and Central Nervous System Tumors Diagnosed in the United States in 2004-2007,” Central Brain Tumor Registry of the United State, 2011.

[2] D. N. Louis, H. Ohgaki, O. D. Wiestler, W. K. Cavenee, P. C. Burger, A. Jouvet, B. W. Scheithauer and P. Kleihues, "The 2007 WHO Classification of Tumours of the Central Nervous System,” Acta Neuropathologica, Vol. 114, No. 2, 2007, pp. 97-109.

doi:10.1007/s00401-007-0243-4

[3] M. D. Walker, E. Alexander Jr., W. E. Hunt, C. S. Maccarty, M. S. Mahaley Jr., J. Mealey Jr., H. A. Norrell, G. Owens, J. Ransohoff, C. B. Wilson, E. A. Gehan and T. A. Strike, "Evaluation of BCNU and/or Radiotherapy in the Treatment of Anaplastic Gliomas. A Cooperative Clinical trial,” Journal of Neurosurgery, Vol. 49, No. 3, 1978, pp. 333-343. doi:10.3171/jns.1978.49.3.0333

[4] M. D. Walker, T. A. Strike and G. E. Sheline, "An Analysis of Dose-Effect Relationship in the Radiotherapy of Malignant Gliomas,” International Journal of Radiation Oncology, Biology, Physics, Vol. 5, No. 10, 1979, pp. 1725-1731. doi:10.1016/0360-3016(79)90553-4

[5] M. D. Walker, S. B. Green, D. P. Byar, E. Alexander Jr., U. Batzdorf, W. H. Brooks, W. E. Hunt, C. S. Maccarty, M. S. Mahaley Jr., J. Mealey Jr., G. Owens, J. Ransohoff, J. T. Robertson, W. R. Shapiro, K. R. Smith Jr., C. B. 
Wilson and T. A. Strike, "Randomized Comparisons of Radiotherapy and Nitrosoureas for the Treatment of Malignant Glioma after Surgery,” The New England Journal of Medicine, Vol. 303, No. 23, 1980, pp. 1323-1329. doi:10.1056/NEJM198012043032303

[6] R. Stupp, W. P. Mason, M. J. Van Den Bent, M. Weller, B. Fisher, M. J. Taphoorn, K. Belanger, A. A. Brandes, C. Marosi, U. Bogdahn, J. Curschmann, R. C. Janzer, S. K. Ludwin, T. Gorlia, A. Allgeier, D. Lacombe, J. G. Cairncross, E. Eisenhauer and R. O. Mirimanoff, "Radiotherapy Plus Concomitant and Adjuvant Temozolomide for Glioblastoma," The New England Journal of Medicine, Vol. 352, No. 10, 2005, pp. 987-996. doi:10.1056/NEJMoa043330

[7] L. A. Stewart, "Chemotherapy in Adult High-Grade Glioma: A Systematic Review and Meta-Analysis of Individual Patient Data from 12 Randomised Trials,” The Lancet, Vol. 359, No. 9311, 2002, pp. 1011-1018. doi:10.1016/S0140-6736(02)08091-1

[8] R. L. Engerman, D. Pfaffenbach and M. D. Davis, "Cell Turnover of Capillaries,” Laboratory Investigation, Vol. 17, No. 6, 1967, pp. 738-743.

[9] B. Hobson and J. Denekamp, "Endothelial Proliferation in Tumours and Normal Tissues: Continuous Labelling Studies,” British Journal of Cancer, Vol. 49, No. 4, 1984, pp. 405-413. doi:10.1038/bjc.1984.66

[10] P. Carmeliet, "Angiogenesis in Life, Disease and Medicine,” Nature, Vol. 438, No. 7070, 2005, pp. 932-936. doi:10.1038/nature04478

[11] J. Folkman, “Tumor Angiogenesis: Therapeutic Implications," The New England Journal of Medicine, Vol. 285, No. 21, 1971, pp. 1182-1186. doi:10.1056/NEJM197111182852108

[12] R. K. Jain, E. Di Tomaso, D. G. Duda, J. S. Loeffler, A. G. Sorensen and T. T. Batchelor, "Angiogenesis in Brain Tumours,” Nature Reviews Neuroscience, Vol. 8, No. 8, 2007, pp. 610-622doi:10.1038/nrn2175

[13] B. Kaur, F. W. Khwaja, E. A. Severson, S. L. Matheny, D. J. Brat and E. G. Van Meir, "Hypoxia and the Hypoxia-Inducible-Factor Pathway in Glioma Growth and Angiogenesis,” Neuro-Oncology, Vol. 7, No. 2, 2005, pp. 134-153. doi:10.1215/S1152851704001115

[14] S. P. Leon, R. D. Folkerth and P. M. Black, "Microvessel Density Is a Prognostic Indicator for Patients with Astroglial Brain Tumors,” Cancer, Vol. 77, No. 2, 1996, pp. 362-372.

doi:10.1002/(SICI)1097-0142(19960115)77:2<362::AIDCNCR20>3.0.CO;2-Z

[15] N. O. Schmidt, M. Westphal, C. Hagel, S. Ergun, D. Stavrou, E. M. Rosen and K. Lamszus, "Levels of Vascular Endothelial Growth Factor, Hepatocyte Growth Factor/Scatter Factor and Basic Fibroblast Growth Factor in Human Gliomas and Their Relation to Angiogenesis," International Journal of Cancer, Vol. 84, No. 1, 1999, pp. 10-18. doi:10.1002/(SICI)1097-0215(19990219)84:1<10::AID-I JC3>3.0.CO;2-L

[16] Y. H. Zhou, F. Tan, K. R. Hess and W. K. Yung, "The Expression of PAX6, PTEN, Vascular Endothelial Growth
Factor, and Epidermal Growth Factor Receptor in Gliomas: Relationship to Tumor Grade and Survival," Clinical Cancer Research, Vol. 9, No. 9, 2003, pp. 33693375.

[17] M. Saleh, K. Vasilopoulos, S. S. Stylli, A. H. Kaye and A. F. Wilks, "The Expression of Antisense Vascular Endothelial Growth Factor (VEGF) Sequences Inhibits Intracranial C6 Glioma Growth in Vivo by Suppressing Tumour Angiogenesis,” Journal of Clinical Neuroscience, Vol. 3, No. 4, 1996, pp. 366-372. doi:10.1016/S0967-5868(96)90035-1

[18] B. A. Reynolds and S. Weiss, "Generation of Neurons and Astrocytes from Isolated Cells of the Adult Mammalian Central Nervous System,” Science, Vol. 255, No. 5052, 1992, pp. 1707-1710. doi:10.1126/science. 1553558

[19] N. Sanai, A. Alvarez-Buylla and M. S. Berger, "Neural Stem Cells and the Origin of Gliomas," The New England Journal of Medicine, Vol. 353, No. 8, 2005, pp. 811-822. doi:10.1056/NEJMra043666

[20] S. K. Singh, C. Hawkins, I. D. Clarke, J. A. Squire, J. Bayani, T. Hide, R. M. Henkelman, M. D. Cusimano and P. B. Dirks, "Identification of Human Brain Tumour Initiating Cells,” Nature, Vol. 432, No. 7015, 2004, pp. 396401. doi:10.1038/nature03128

[21] P. B. Dirks, "Brain Tumor Stem Cells: Bringing Order to the Chaos of Brain Cancer," Journal of Clinical Neuroscience, Vol. 26, No. 17, 2008, pp. 2916-2924. doi:10.1200/JCO.2008.17.6792

[22] S. Bao, Q. Wu, R. E. Mclendon, Y. Hao, Q. Shi, A. B. Hjelmeland, M. W. Dewhirst, D. D. Bigner and J. N. Rich, "Glioma Stem Cells Promote Radioresistance by Preferential Activation of the DNA Damage Response," Nature, Vol. 444, No. 7120, 2006, pp. 756-760. doi:10.1038/nature05236

[23] G. Liu, X. Yuan, Z. Zeng, P. Tunici, H. Ng, I. R. Abdulkadir, L. Lu, D. Irvin, K. L. Black and J. S. Yu, “Analysis of Gene Expression and Chemoresistance of CD133+ Cancer Stem Cells in Glioblastoma,” Molecular Cancer, Vol. 5, 2006, p. 67. doi:10.1186/1476-4598-5-67

[24] A. Salmaggi, A. Boiardi, M. Gelati, A. Russo, C. Calatozzolo, E. Ciusani, F. L. Sciacca, A. Ottolina, E. A. Parati, C. La Porta, G. Alessandri, C. Marras, D. Croci and M. De Rossi, “Glioblastoma-Derived Tumorospheres Identify a Population of Tumor Stem-Like Cells with Angiogenic Potential and Enhanced Multidrug Resistance Phenotype,” Glia, Vol. 54, No. 8, 2006, pp. 850-860. doi:10.1002/glia.20414

[25] M. Dean, T. Fojo and S. Bates, "Tumour Stem Cells and Drug Resistance,” Nature Reviews Cancer, Vol. 5, No. 4, 2005, pp. 275-284. doi:10.1038/nrc1590

[26] S. Bao, Q. Wu, S. Sathornsumetee, Y. Hao, Z. Li, A. B. Hjelmeland, Q. Shi, R. E. Mclendon, D. D. Bigner and J. N. Rich, "Stem Cell-Like Glioma Cells Promote Tumor Angiogenesis through Vascular Endothelial Growth Factor," Cancer Research, Vol. 66, No. 16, 2006, pp. 78437848. doi:10.1158/0008-5472.CAN-06-1010

[27] C. Folkins, Y. Shaked, S. Man, T. Tang, C. R. Lee, Z. Zhu, R. M. Hoffman and R. S. Kerbel, "Glioma Tumor Stem-Like Cells Promote Tumor Angiogenesis and Vas- 
culogenesis via Vascular Endothelial Growth Factor and Stromal-Derived Factor 1," Cancer Reseaarch, Vol. 69, No. 18, 2009, pp. 7243-7251. doi:10.1158/0008-5472.CAN-09-0167

[28] N. Oka, A. Soeda, A. Inagaki, M. Onodera, H. Maruyama, A. Hara, T. Kunisada, H. Mori and T. Iwama, "VEGF Promotes Tumorigenesis and Angiogenesis of Human Glioblastoma Stem Cells,” Biochemical and Biophysical Research Communications, Vol. 360, No. 3, 2007, pp. 553-559. doi:10.1016/j.bbrc.2007.06.094

[29] L. G. Presta, H. Chen, S. J. O’connor, V. Chisholm, Y. G. Meng, L. Krummen, M. Winkler and N. Ferrara, "Humanization of an Anti-Vascular Endothelial Growth Factor Monoclonal Antibody for the Therapy of Solid Tumors and Other Disorders," Cancer Research, Vol. 57, No. 20, 1997, pp. 4593-4599.

[30] N. Ferrara, K. J. Hillan, H. P. Gerber and W. Novotny, "Discovery and Development of Bevacizumab, an AntiVEGF Antibody for Treating Cancer," Nature Reviews Drug Discovery, Vol. 3, No. 5, 2004, pp. 391-400 doi:10.1038/nrd1381

[31] M. H. Cohen, Y. L. Shen, P. Keegan and R. Pazdur, "FDA Drug Approval Summary: Bevacizumab (Avastin) as Treatment of Recurrent Glioblastoma Multiforme,” The Oncologist, Vol. 14, No. 11, 2009, pp. 1131-1138. doi:10.1634/theoncologist.2009-0121

[32] J. J. Vredenburgh, A. Desjardins, J. E. Herndon, J. Marcello, D. A. Reardon, J. A. Quinn, J. N. Rich, S. Sathornsumetee, S. Gururangan, J. Sampson, M. Wagner, L. Bailey, D. D. Bigner, A. H. Friedman and H. S. Friedman, "Bevacizumab Plus Irinotecan in Recurrent Glioblastoma Multiforme,” Journal of Clinical Oncology, Vol. 25, No. 30, 2007, pp. 4722-4729. doi:10.1200/JCO.2007.12.2440

[33] H. S. Friedman, M. D. Prados, P. Y. Wen, T. Mikkelsen, D. Schiff, L. E. Abrey, W. K. Yung, N. Paleologos, M. K. Nicholas, R. Jensen, J. Vredenburgh, J. Huang, M. Zheng and T. Cloughesy, "Bevacizumab alone and in Combination with Irinotecan in Recurrent Glioblastoma," Journal of Clinical Oncology, Vol. 27, No. 28, 2009, pp. 47334740. doi:10.1200/JCO.2008.19.8721

[34] W. Wick, M. Weller, M. Van Den Bent and R. Stupp, "Bevacizumab and Recurrent Malignant Gliomas: A European Perspective," Journal of Clinical Oncology, Vol. 28, No. 12, 2010, pp. e188-e189. doi:10.1200/JCO.2009.26.9027

[35] D. A. Reardon, A. Desjardins, K. B. Peters, S. Gururangan, J. H. Sampson, R. E. Mclendon, J. E. Herndon, A. Bulusu, S. Threatt, A. H. Friedman, J. J. Vredenburgh and H. S. Friedman, "Phase II Study of Carboplatin, Irinotecan, and Bevacizumab for Bevacizumab Naive, Recurrent Glioblastoma," Journal of Neurooncology, Vol. 107, No. 1, 2012, pp. 155-164. doi:10.1007/s11060-011-0722-2

[36] D. A. Reardon, A. Desjardins, K. B. Peters, J. J. Vredenburgh, S. Gururangan, J. H. Sampson, R. E. Mclendon, J. E. Herndon, A. Coan, S. Threatt, A. H. Friedman and H. S. Friedman, "Phase 2 Study of Carboplatin, Irinotecan, and Bevacizumab for Recurrent Glioblastoma after Progression on Bevacizumab Therapy,” Cancer, Vol. 117,
No. 23, 2011, pp. 5351-5358. doi:10.1002/cncr.26188

[37] D. A. Reardon, A. Desjardins, K. Peters, S. Gururangan, J. Sampson, J. N. Rich, R. Mclendon, J. E. Herndon, J. Marcello, S. Threatt, A. H. Friedman, J. J. Vredenburgh and H. S. Friedman, "Phase II Study of Metronomic Chemotherapy with Bevacizumab for Recurrent Glioblastoma after Progression on Bevacizumab Therapy," Journal of Neurooncology, Vol. 103, No. 2, 2011, pp. 371-379. doi:10.1007/s11060-010-0403-6

[38] A. Desjardins, D. A. Reardon, A. Coan, J. Marcello, J. E. Herndon, L. Bailey, K. B. Peters, H. S. Friedman and J. J. Vredenburgh, "Bevacizumab and Daily Temozolomide for Recurrent Glioblastoma,” Cancer, Vol. 118, No. 5, 2011, pp. 1302-1312. doi:10.1002/cncr.26381

[39] D. A. Reardon, A. Desjardins, J. J. Vredenburgh, S. Gururangan, J. H. Sampson, S. Sathornsumetee, R. E. Mclendon, J. E. Herndon, J. E. Marcello, J. Norfleet, A. H. Friedman, D. D. Bigner and H. S. Friedman, "Metronomic Chemotherapy with Daily, Oral Etoposide Plus Bevacizumab for Recurrent Malignant Glioma: A Phase II Study,” British Journal of Cancer, Vol. 101, No. 12, 2009, pp. 1986-1994. doi:10.1038/sj.bjc.6605412

[40] S. Sathornsumetee, A. Desjardins, J. J. Vredenburgh, R. E. Mclendon, J. Marcello, J. E. Herndon, A. Mathe, M. Hamilton, J. N. Rich, J. A. Norfleet, S. Gururangan, H. S. Friedman and D. A. Reardon, "Phase II Trial of Bevacizumab and Erlotinib in Patients with Recurrent Malignant Glioma,” Neuro-Oncology, Vol. 12, No. 12, 2010, pp. 1300-1310. doi:10.1093/neuonc/noq099

[41] B. Hasselbalch, U. Lassen, S. Hansen, M. Holmberg, M. Sorensen, M. Kosteljanetz, H. Broholm, M. T. Stockhausen and H. S. Poulsen, "Cetuximab, Bevacizumab, and Irinotecan for Patients with Primary Glioblastoma and Progression after Radiation Therapy and Temozolomide: A Phase II Trial,” Neuro-Oncology, Vol. 12, No. 5, 2010, pp. 508-516. doi:10.1093/neuonc/nop063

[42] V. Stark-Vance, "Bevacizumab and CPT-11 in the Treatment of Relapsed Maliganant Glioma,” Neuro-Oncology, Vol. 369, No. 7, 2005, Abstract 342.

[43] W. B. Pope, A. Lai, P. Nghiemphu, P. Mischel and T. F. Cloughesy, "MRI in Patients with High-Grade Gliomas Treated with Bevacizumab and Chemotherapy," Neurology, Vol. 66, No. 8, 2006, pp. 1258-1260. doi:10.1212/01.wnl.0000250628.10420.d8

[44] J. J. Vredenburgh, A. Desjardins, J. E. Herndon, J. M. Dowell, D. A. Reardon, J. A. Quinn, J. N. Rich, S. Sathornsumetee, S. Gururangan, M. Wagner, D. D. Bigner, A. H. Friedman and H. S. Friedman, "Phase II Trial of Bevacizumab and Irinotecan in Recurrent Malignant Glioma,” Clinical Cancer Research, Vol. 13, No. 4, 2007, pp. 1253-1259. doi:10.1158/1078-0432.CCR-06-2309

[45] A. D. Norden, G. S. Young, K. Setayesh, A. Muzikansky, R. Klufas, G. L. Ross, A. S. Ciampa, L. G. Ebbeling, B. Levy, J. Drappatz, S. Kesari and P. Y. Wen, "Bevacizumab for Recurrent Malignant Gliomas: Efficacy, Toxicity, and Patterns of Recurrence,” Neurology, Vol. 70, No. 10, 2008, pp. 779-787. doi:10.1212/01.wnl.0000339387.03225.0a

[46] A. Narayana, P. Kelly, J. Golfinos, E. Parker, G. Johnson, 
E. Knopp, D. Zagzag, I. Fischer, S. Raza, P. Medabalmi, P. Eagan and M. L. Gruber, "Antiangiogenic Therapy Using Bevacizumab in Recurrent High-Grade Glioma: Impact on Local Control and Patient Survival," Journal of Neurosurgery, Vol. 110, No. 1, 2009, pp. 173-180 doi:10.3171/2008.4.17492

[47] P. L. Nghiemphu, W. Liu, Y. Lee, T. Than, C. Graham, A. Lai, R. M. Green, W. B. Pope, L. M. Liau, P. S. Mischel, S. F. Nelson, R. Elashoff and T. F. Cloughesy, "Bevacizumab and Chemotherapy for Recurrent Glioblastoma: A Single-Institution Experience,” Neurology, Vol. 72, No. 14, 2009, pp. 1217-1222. doi:10.1212/01.wnl.0000345668.03039.90

[48] H. S. Poulsen, K. Grunnet, M. Sorensen, P. Olsen, B. Hasselbalch, K. Nelausen, M. Kosteljanetz and U. Lassen, "Bevacizumab Plusirinotecan in the Treatment Patients with Progressive Recurrent Malignant Brain Tumours,” Acta Oncology, Vol. 48, No. 1, 2009, pp. 52-58. doi:10.1080/02841860802537924

[49] R. M. Zuniga, R. Torcuator, R. Jain, J. Anderson, T. Doyle, S. Ellika, L. Schultz and T. Mikkelsen, "Efficacy, Safety and Patterns of Response and Recurrence in Patients with Recurrent High-Grade Gliomas Treated with Bevacizumab Plus Irinotecan,” Journal of Neurooncology, Vol. 91, No. 3, 2009, pp. 329-336. doi:10.1007/s11060-008-9718-y

[50] M. R. Gilbert, "RTOG 0625: A Phase II Study of Bevacizumab with Irinotecan in Recurrent Glioblastoma (GBM) [Abstract]," Journal of Clinical Oncology, Vol. 27, Suppl. 15, 2009, Abstract 2011.

[51] P. H. Gutin, F. M. Iwamoto, K. Beal, N. A. Mohile, S. Karimi, B. L. Hou, S. Lymberis, Y. Yamada, J. Chang and L. E. Abrey, "Safety and Efficacy of Bevacizumab with Hypofractionated Stereotactic Irradiation for Recurrent Malignant Gliomas,” International Journal of Radiation Oncology, Biology, Physics, Vol. 75, No. 1, 2009, pp. 156-163. doi:10.1016/j.jjrobp.2008.10.043

[52] T. N. Kreisl, L. Kim, K. Moore, P. Duic, C. Royce, I. Stroud, N. Garren, M. Mackey, J. A. Butman, K. Camphausen, J. Park, P. S. Albert and H. A. Fine, "Phase II trial of Single-Agent Bevacizumab Followed by Bevacizumab Plus Irinotecan at Tumor Progression in Recurrent Glioblastoma,” Journal of Clinical Oncology, Vol.27, No. 5, 2009, pp. 740-745. doi:10.1200/JCO.2008.16.3055

[53] M. C. Chamberlain and S. K. Johnston, “Salvage Therapy with Single Agent Bevacizumab for Recurrent Glioblastoma,” Journal of Neurooncology, Vol. 96, No. 2, 2010, pp. 259-269. doi:10.1007/s11060-009-9957-6

[54] J. J. Raizer, S. Grimm, M. C. Chamberlain, M. K. Nicholas, J. P. Chandler, K. Muro, S. Dubner, A. W. Rademaker, J. Renfrow and M. Bredel, "A Phase 2 Trial of Single-Agent Bevacizumab Given in an Every-3-Week Schedule for Patients with Recurrent High-Grade Gliomas," Cancer, Vol. 116, No. 22, 2010, pp. 5297-5305. doi:10.1002/cncr.25462

[55] L. M. Ellis and D. J. Hicklin, "Pathways Mediating Resistance to Vascular Endothelial Growth Factor-Targeted Therapy," Clinical Cancer Research, Vol. 14, No. 20, 2008, pp. 6371-6375.

\section{doi:10.1158/1078-0432.CCR-07-5287}

[56] E. Hattingen, A. Jurcoane, O. Bahr, J. Rieger, J. Magerkurth, S. Anti, J. P. Steinbach and U. Pilatus, "Bevacizumab Impairs Oxidative Energy Metabolism and Shows Antitumoral Effects in Recurrent Glioblastomas: A 31P/1H MRSI and Quantitative Magnetic Resonance Imaging Study,” Neuro-Oncology, Vol. 13, No. 12, 2011, pp. 1349-1363. doi:10.1093/neuonc/nor132

[57] R. K. Jain, "Normalization of Tumor Vasculature: An Emerging Concept in Antiangiogenic Therapy,” Science, Vol. 307, No. 5706, 2005, pp. 58-62. doi:10.1126/science.1104819

[58] O. Keunen, M. Johansson, A. Oudin, M. Sanzey, S. A. Rahim, F. Fack, F. Thorsen, T. Taxt, M. Bartos, R. Jirik, H. Miletic, J. Wang, D. Stieber, L. Stuhr, I. Moen, C. B. Rygh, R. Bjerkvig and S. P. Niclou, "Anti-VEGF Treatment Reduces Blood Supply and Increases Tumor Cell Invasion in Glioblastoma," Proceedings of the National Academy Sciences of the United States of America, Vol. 108, No. 9, 2011, pp. 3749-3754. doi:10.1073/pnas.1014480108

[59] J. Ma, S. Pulfer, S. Li, J. Chu, K. Reed and J. M. Gallo, "Pharmacodynamic-Mediated Reduction of Temozolomide Tumor Concentrations by the Angiogenesis Inhibitor TNP-470," Cancer Research, Vol. 61, No. 14, 2001, pp. 5491-5498.

[60] R. Murata, Y. Nishimura and M. Hiraoka, “An Antiangiogenic Agent (TNP-470) Inhibited Reoxygenation during Fractionated Radiotherapy of Murine Mammary Carcinoma," International Journal of Radiation Oncology, Biology, Physics, Vol. 37, No. 5, 1997, pp. 1107-1113. doi:10.1016/S0360-3016(96)00628-1

[61] B. M. Fenton, S. F. Paoni and I. Ding, "Effect of VEGF Receptor-2 Antibody on Vascular Function and Oxygenation in Spontaneous and Transplanted Tumors," Radiotherapy \& Oncology, Vol. 72, No. 2, 2004, pp. 221-230. doi:10.1016/j.radonc.2004.05.005

[62] A. A. Van Der Veldt, M. Lubberink, I. Bahce, M. Walraven, M. P. De Boer, H. N. Greuter, N. H. Hendrikse, J. Eriksson, A. D. Windhorst, P. E. Postmus, H. M. Verheul, E. H. Serne, A. A. Lammertsma and E. F. Smit, "Rapid Decrease in Delivery of Chemotherapy to Tumors after Anti-VEGF Therapy: Implications for Scheduling of Anti-Angiogenic Drugs," Cancer Cell, Vol. 21, No. 1, 2012, pp. 82-91. doi:10.1016/j.ccr.2011.11.023

[63] O. Casanovas, D. J. Hicklin, G. Bergers and D. Hanahan, "Drug Resistance by Evasion of Antiangiogenic Targeting of VEGF Signaling in Late-Stage Pancreatic Islet Tumors," Cancer Cell, Vol. 8, No. 4, 2005, pp. 299-309. doi:10.1016/j.ccr.2005.09.005

[64] A. K. Lucio-Eterovic, Y. Piao and J. F. De Groot, "Mediators of Glioblastoma Resistance and Invasion during Antivascular Endothelial Growth Factor Therapy,” Clinical Cancer Research, Vol. 15, No. 14, 2009, pp. 45894599. doi:10.1158/1078-0432.CCR-09-0575

[65] R. K. Jain, D. G. Duda, J. W. Clark and J. S. Loeffler, "Lessons from Phase III Clinical Trials on Anti-VEGF Therapy for Cancer,” Nature Clinical Practice Oncology, Vol. 3, No. 1, 2006, pp. 24-40. doi:10.1038/ncponc0403 
[66] W. B. Nagengast, M. N. Lub-De Hooge, S. F. Oosting, W. F. Den Dunnen, F. J. Warnders, A. H. Brouwers, J. R. De Jong, P. M. Price, H. Hollema, G. A. Hospers, P. H. Elsinga, J. W. Hesselink, J. A. Gietema and E. G. De Vries, "VEGF-PET Imaging Is a Noninvasive Biomarker Showing Differential Changes in the Tumor during Sunitinib Treatment," Cancer Research, Vol. 71, No. 1, 2011, pp. 143-153. doi:10.1158/0008-5472.CAN-10-1088

[67] P. Carmeliet and R. K. Jain, "Molecular Mechanisms and Clinical Applications of Angiogenesis," Nature, Vol. 473, No. 7347, 2011, pp. 298-307. doi:10.1038/nature10144

[68] M. Franco, P. Roswall, E. Cortez, D. Hanahan and K. Pietras, "Pericytes Promote Endothelial Cell Survival through Induction of Autocrine VEGF-A Signaling and Bcl-w Expression,” Blood, Vol. 118, No. 10, 2011, pp. 2906-2917. doi:10.1182/blood-2011-01-331694

[69] N. Ferrara, "Pathways Mediating VEGF-Independent Tumor Angiogenesis," Cytokine Growth Factor Reviews, Vol. 21, No. 1, 2010, pp. 21-26. doi:10.1016/j.cytogfr.2009.11.003

[70] S. Song, A. J. Ewald, W. Stallcup, Z. Werb and G. Bergers, "PDGFR Beta+ Perivascular Progenitor Cells in Tumours Regulate Pericyte Differentiation and Vascular Survival,” Nature Clinical Practice Oncology, Vol. 7, No. 9, 2005, pp. 870-879. doi:10.1038/ncb1288

[71] S. Pennacchietti, P. Michieli, M. Galluzzo, M. Mazzone, S. Giordano and P. M. Comoglio, "Hypoxia Promotes Invasive Growth by Transcriptional Activation of the Met Protooncogene," Cancer Cell, Vol. 3, No. 4, 2003, pp. 347-361. doi:10.1016/S1535-6108(03)00085-0

[72] C. Birchmeier and E. Gherardi, "Developmental Roles of HGF/SF and Its Receptor, the c-Met Tyrosine Kinase," Trends in Cell Biology, Vol. 8, No. 10, 1998, pp. 404410. doi:10.1016/S0962-8924(98)01359-2

[73] T. Nakamura, S. Mizuno, K. Matsumoto, Y. Sawa and H. Matsuda, "Myocardial Protection from Is Chemia/Reperfusion Injury by Endogenous and Exogenous HGF," Journal of Clinical Investigation, Vol. 106, No. 12, 2000, pp. 1511-1519. doi:10.1172/JCI10226

[74] C. G. Huh, V. M. Factor, A. Sanchez, K. Uchida, E. A. Conner and S. S. Thorgeirsson, "Hepatocyte Growth Factor/c-Met Signaling Pathway is Required for Efficient Liver Regeneration and Repair," Proceedings of the National Academy Sciences of the United States of America, Vol. 101, No. 13, 2004, pp. 4477-4482. doi:10.1073/pnas.0306068101

[75] P. Kunkel, S. Muller, P. Schirmacher, D. Stavrou, R. Fillbrandt, M. Westphal and K. Lamszus, "Expression and Localization of Scatter Factor/Hepatocyte Growth Factor in Human Astrocytomas,” Neuro-Oncology, Vol. 3, No. 2, 2001, pp. 82-88. doi:10.1093/neuonc/3.2.82

[76] S. Koochekpour, M. Jeffers, S. Rulong, G. Taylor, E. Klineberg, E. A. Hudson, J. H. Resau and G. F. Vande Woude, "Met and Hepatocyte Growth Factor/Scatter Factor Expression in Human Gliomas," Cancer Research, Vol. 57, No. 23, 1997, pp. 5391-5398.

[77] T. Martens, N. O. Schmidt, C. Eckerich, R. Fillbrandt, M. Merchant, R. Schwall, M. Westphal and K. Lamszus, “A Novel One-Armed Anti-c-Met Antibody Inhibits Glioblas- toma Growth in Vivo," Clinical Cancer Research, Vol. 12, No. 20, 2006, pp. 6144-6152.

doi:10.1158/1078-0432.CCR-05-1418

[78] Genentech, "A Study of the Safety and Pharmacology of MetMAb (PRO143966), a Monovalent Antagonist Antibody to the Receptor C-Met, Administered Intravenously in Patients with Locally Advanced or Metastatic Solid Tumors,” 2010. http://clinicaltrials.gov/ct2/show/NCT01068977.

[79] Pfizer, “A Study of Oral PF-02341066, A c-Met/Hepatocyte Growth Factor Tyrosine Kinase Inhibitor, in Patients with Advanced Cancer,” 2007-2012. http://clinicaltrials.gov/ct2/show/NCT00585195.

[80] P. Y. Wen, D. Schiff, T. F. Cloughesy, J. J. Raizer, J. Laterra, M. Smitt, M. Wolf, K. S. Oliner, A. Anderson, M. Zhu, E. Loh and D. A. Reardon, "A Phase II Study Evaluating the Efficacy and Safety of AMG 102 (Rilotumumab) in Patients with Recurrent Glioblastoma," Neuro-Oncology, Vol. 13, No. 4, 2011, pp. 437-446. doi:10.1093/neuonc/noq198

[81] D. University, "AMG 102 and Avastin for Recurrent Malignant Glioma,” 2010-2012. http://clinicaltrials.gov/ct2/show/NCT01113398.

[82] T. T. Batchelor, A. G. Sorensen, E. Di Tomaso, W. T. Zhang, D. G. Duda, K. S. Cohen, K. R. Kozak, D. P. Cahill, P. J. Chen, M. Zhu, M. Ancukiewicz, M. M. Mrugala, S. Plotkin, J. Drappatz, D. N. Louis, P. Ivy, D. T. Scadden, T. Benner, J. S. Loeffler, P. Y. Wen and R. K. Jain, “AZD2171, a Pan-VEGF Receptor Tyrosine Kinase Inhibitor, Normalizes Tumor Vasculature and Alleviates Edema in Glioblastoma Patients," Cancer Cell, Vol. 11, No. 1, 2007, pp. 83-95. doi:10.1016/j.ccr.2006.11.021

[83] M. Relf, S. Lejeune, P. A. Scott, S. Fox, K. Smith, R. Leek, A. Moghaddam, R. Whitehouse, R. Bicknell and A. L. Harris, "Expression of the Angiogenic Factors Vascular Endothelial Cell Growth Factor, Acidic and Basic Fibroblast Growth Factor, Tumor Growth Factor Beta-1, Platelet-Derived Endothelial Cell Growth Factor, Placenta Growth Factor, and Pleiotrophin in Human Primary Breast Cancer and Its Relation to Angiogenesis," Cancer Research, Vol. 57, No. 5, 1997, pp. 963-969.

[84] R. Rahman, S. Smith, C. Rahman and R. Grundy, "Antiangiogenic Therapy and Mechanisms of Tumor Resistance in Malignant Glioma,” Journal of Oncology, Vol. 2010, 2010, Article ID: 251231 doi:10.1155/2010/251231

[85] J. M. Heddleston, Z. Li, R. E. Mclendon, A. B. Hjelmeland and J. N. Rich, "The Hypoxic Microenvironment Maintains Glioblastoma Stem Cells and Promotes Reprogramming towards a Cancer Stem Cell Phenotype," Cell Cycle, Vol. 8, No. 20, 2009, pp. 3274-3284. doi:10.4161/cc.8.20.9701

[86] A. Soeda, M. Park, D. Lee, A. Mintz, A. Androutsellis-Theotokis, R. D. Mckay, J. Engh, T. Iwama, T. Kunisada, A. B. Kassam, I. F. Pollack and D. M. Park, "Hypoxia Promotes Expansion of the CD133-Positive Glioma Stem Cells through Activation of HIF-1 Alpha," Oncogene, Vol. 28, No. 45, 2009, pp. 3949-3959. doi:10.1038/onc.2009.252

[87] G. L. Semenza, "HIF-1 and Tumor Progression: Patho- 
physiology and Therapeutics," Trends in Molecular Medicine, Vol. 8, No. 4, 2002, pp. S62-S67. doi:10.1016/S1471-4914(02)02317-1

[88] D. P. Brazil, J. Park and B. A. Hemmings, "PKB Binding Proteins. Getting in on the Akt," Cell, Vol. 111, No. 3, 2002, pp. 293-303. doi:10.1016/S0092-8674(02)01083-8

[89] I. Galetic, M. Andjelkovic, R. Meier, D. Brodbeck, J. Park and B. A. Hemmings, "Mechanism of Protein Kinase B Activation by Insulin/Insulin-Like Growth Factor-1 Revealed by Specific Inhibitors of Phosphoinositide 3-Kinase-Significance for Diabetes and Cancer," Pharmacology \& Therapeutics, Vol. 82, No. 2-3, 1999, pp. 409-425. doi:10.1016/S0163-7258(98)00071-0

[90] D. Koul, R. Shen, Y. W. Kim, Y. Kondo, Y. Lu, J. Bankson, S. M. Ronen, D. L. Kirkpatrick, G. Powis and W. K. Yung, "Cellular and in Vivo Activity of a Novel PI3K Inhibitor, PX-866, against Human Glioblastoma,” NeuroOncology, Vol. 12, No. 6, 2010, pp. 559-569. doi:10.1093/neuonc/nop058

[91] G. Prasad, T. Sottero, X. Yang, S. Mueller, C. D. James, W. A. Weiss, M. Y. Polley, T. Ozawa, M. S. Berger, D. T. Aftab, M. D. Prados and D. A. Haas-Kogan, "Inhibition of PI3K/mTOR Pathways in Glioblastoma and Implications for Combination Therapy with Temozolomide," Neuro-Oncology, Vol. 13, No. 4, 2011, pp. 384-392. doi:10.1093/neuonc/noq193

[92] N. Zhang, P. Wei, A. Gong, W. T. Chiu, H. T. Lee, H. Colman, H. Huang, J. Xue, M. Liu, Y. Wang, R. Sawaya, K. Xie, W. K. Yung, R. H. Medema, X. He and S. Huang, "FoxM1 Promotes Beta-Catenin Nuclear Localization and Controls Wnt Target-Gene Expression and Glioma Tumorigenesis," Cancer Cell, Vol. 20, No. 4, 2011, pp. 427-442. doi:10.1016/j.ccr.2011.08.016

[93] T. Pulvirenti, M. Van Der Heijden, L. A. Droms, J. T. Huse, V. Tabar and A. Hall, "Dishevelled 2 Signaling Promotes Self-Renewal and Tumorigenicity in Human Gliomas," Cancer Research, Vol. 71, No. 23, 2011, pp. 7280-7290. doi:10.1158/0008-5472.CAN-11-1531

[94] W. Roth, C. Wild-Bode, M. Platten, C. Grimmel, H. S. Melkonyan, J. Dichgans and M. Weller, "Secreted Frizzled-Related Proteins Inhibit Motility and Promote Growth of Human Malignant Glioma Cells,” Oncogene, Vol. 19, No. 37, 2000, pp. 4210-4220. doi:10.1038/sj.onc.1203783

[95] J. Satoh and Y. Kuroda, "Beta-Catenin Expression in Human Neural Cell Lines Following Exposure to Cytokines and Growth Factors," Neuropathology, Vol. 20, No. 2, 2000, pp. 113-123. doi:10.1046/j.1440-1789.2000.00293.X

[96] C. Liu, Y. Tu, X. Sun, J. Jiang, X. Jin, X. Bo, Z. Li, A. Bian, X. Wang, D. Liu, Z. Wang and L. Ding, "Wnt/ Beta-Catenin Pathway in Human Glioma: Expression Pattern and Clinical/Prognostic Correlations," Clinical and Experimental Medicine, Vol. 11, No. 2, 2011, pp. 105-112. doi:10.1007/s10238-010-0110-9

[97] W. L. Lambiv, I. Vassallo, M. Delorenzi, T. Shay, A. C. Diserens, A. Misra, B. Feuerstein, A. Murat, E. Migliavacca, M. F. Hamou, D. Sciuscio, R. Burger, E. Domany, R. Stupp and M. E. Hegi, “The Wnt Inhibitory
Factor 1 (WIF1) Is Targeted in Glioblastoma and Has a Tumor Suppressing Function Potentially by Induction of Senescence,” Neuro-Oncology, Vol. 13, No. 7, 2011, pp. 736-747. doi:10.1093/neuonc/nor036

[98] M. Kamino, M. Kishida, T. Kibe, K. Ikoma, M. Iijima, H. Hirano, M. Tokudome, L. Chen, C. Koriyama, K. Yamada, K. Arita and S. Kishida, "Wnt-5a Signaling is Correlated with Infiltrative Activity in Human Glioma by Inducing Cellular Migration and MMP-2," Cancer Science, Vol. 102, No. 3, 2011, pp. 540-548. doi:10.1111/j.1349-7006.2010.01815.x

[99] G. Foltz, J. G. Yoon, H. Lee, L. Ma, Q. Tian, L. Hood and A. Madan, "Epigenetic Regulation of Wnt Pathway Antagonists in Human Glioblastoma Multiforme," Genes Cancer, Vol. 1, No. 1, 2010, pp. 81-90. doi:10.1177/1947601909356103

[100] R. M. Zuniga, R. Torcuator, R. Jain, J. Anderson, T. Doyle, L. Schultz and T. Mikkelsen, "Rebound Tumour Progression after the Cessation of Bevacizumab Therapy in Patients with Recurrent High-Grade Glioma,” Journal of Neuro-Oncology, Vol. 99, No. 2, 2010, pp. 237-242. doi:10.1007/s11060-010-0121-0

[101] S. D. Rose and M. K. Aghi, "Mechanisms of Evasion to Antiangiogenic Therapy in Glioblastoma," Clinical Neurosurgery, Vol. 57, No. 2010, pp. 123-128.

[102] M. Paez-Ribes, E. Allen, J. Hudock, T. Takeda, H. Okuyama, F. Vinals, M. Inoue, G. Bergers, D. Hanahan and O. Casanovas, "Antiangiogenic Therapy Elicits Malignant Progression of Tumors to Increased Local Invasion and Distant Metastasis," Cancer Cell, Vol. 15, No. 3, 2009, pp. 220-231. doi:10.1016/j.ccr.2009.01.027

[103] A. Wick, N. Dorner, N. Schafer, S. Hofer, S. Heiland, D. Schemmer, M. Platten, M. Weller, M. Bendszus and W. Wick, "Bevacizumab Does Not Increase the Risk of Remote Relapse in Malignant Glioma,” Annals of Neurology, Vol. 69, No. 3, 2011, pp. 586-592. doi:10.1002/ana.22336

[104] E. C. Quant, A. D. Norden, J. Drappatz, A. Muzikansky, L. Doherty, D. Lafrankie, A. Ciampa, S. Kesari and P. Y. Wen, "Role of a Second Chemotherapy in Recurrent Malignant Glioma Patients who Progress on Bevacizumab," Neuro-Oncology, Vol. 11, No. 5, 2009, pp. 550-555. doi:10.1215/15228517-2009-006

[105] O. Warburg, "On the Origin of Cancer Cells,” Science, Vol. 123, No. 3191, 1956, pp. 309-314. doi:10.1126/science.123.3191.309

[106] D. Hanahan and R. A. Weinberg, "Hallmarks of Cancer: the Next Generation,” Cell, Vol. 144, No. 5, 2011, pp. 646-674 doi:10.1016/j.cell.2011.02.013

[107] A. King and E. Gottlieb, "Glucose Metabolism and Programmed Cell Death: An Evolutionary and Mechanistic Perspective," Current Opinion in Cell Biology, Vol. 21, No. 6, 2009, pp. 885-893. doi:10.1016/j.ceb.2009.09.009

[108] R. A. Cairns, I. S. Harris and T. W. Mak, "Regulation of Cancer Cell Metabolism,” Nature Reviews Cancer, Vol. 11, No. 2, 2011, pp. 85-95. doi:10.1038/nrc2981

[109] S. Gupta, A. Farooque, J. S. Adhikari, S. Singh and B. S. Dwarakanath, "Enhancement of Radiation and Chemotherapeutic Drug Responses by 2-Deoxy-D-Glucose in Animal Tumors," Journal of Cancer Research and 
Therapeutics, Vol. 5, Suppl. 1, 2009, pp. S16-S20. doi:10.4103/0973-1482.55135

[110] J. M. Chang, J. W. Chung, H. J. Jae, H. Eh, K. R. Son, K. C. Lee and J. H. Park, "Local Toxicity of Hepatic Arterial Infusion of Hexokinase II Inhibitor, 3-Bromopyruvate: In Vivo Investigation in Normal Rabbit Model," Academic Radiology, Vol. 14, No. 1, 2007, pp. 85-92.

doi:10.1016/j.acra.2006.09.059
[111] D. Stieber, S. A. Abdul Rahim and S. P. Niclou, "Novel Ways to Target Brain Tumour Metabolism," Expert Opinion on Therapeutic Targets, Vol. 15, No. 10, 2011, pp. 1227-1239. doi:10.1517/14728222.2011.588211

[112] Roche, “A Study of Avastin (Bevacizumab) in Combination with Temozolomide and Radiotherapy in Patients with Newly Diagnosed Glioblastoma,” 2009-2012. http://www.clinicaltrials.gov/show/NCT00943826. 